\title{
Self-Medication Awareness for Skin Rash Management by Indian University Students - A Questionnaire-Based Survey Study
}

\author{
Tamilvanan Shunmugaperumal*, Malonje Daka, Puja Chanda \\ Department of Pharmaceutics, Lovely School of Pharmaceutical Sciences, Lovely Professional University, Jalandhar-New Delhi \\ G.T.Road (NH-1), Phagwara, Jalandhar, Punjab, INDIA.
}

\begin{abstract}
The aim of the questionnaire-based study was to survey on the awareness and usage of topical over-the-counter (OTC) products used for the management of skin rash conditions by Indian University students along with their knowledge about the product's safety, contraindications and adverse effects. One hundred and fourty five student members (comprising of 86 of them from pharmacy stream and 59 of them belongs to other department) of which 76 were female, took part in this survey study. The average age of participants was 21.5 years. A questionnaire was developed comprising of 14 questions under three sections including socio-demograpic and economic data (age, gender and education), frequency of topical OTC product usage and allopathic or ayurvedic product information. Out of 14 questions, 4 questions were close ended questions and 10 were open-ended questions. Five percent participants experienced some types of skin rash depending on the environmental and climatic changes. Both allopathic- and ayurvedicbased dosage forms such as creams, gels, ointment, etc were the used products for the skin rash management by the participants. Seventy one percent participants comprising of non-pharmacy students were unaware of any undesirable affects and sixty nine percent (comprising of $82 \%$ pharmacist and $5 \%$ non-pharmacists) were affirmative that ayurvedic-based products had no adverse effects. This indicates that the participants had no discrimination between the allopathic and ayurvedic topical formulation for the management of skin rash condition. It can be concluded that although self-medication awareness to treat their skin rash conditions is fairly reached to the student communities, the consumers should read the drug safety profile through leaflet information present inside the package of the topical OTC formulations.
\end{abstract}

Key words: Allopathic, Ayurvedic, Skin rash, Topical, Survey, Awareness.

\section{INTRODUCTION}

Skin rash is a visible condition wherein the skin gets swollen and irritated by the influence of either the intake and the contact of toxic chemicals, sun rays, harmful microorganisms or the exposure to heavy metals, noxious gases and waste products from chemical and leather industries. The person affected by skin rash conditions usually have scaly or red skin, skin bumps and burning itchy skin (extracted from http://www.everydayhealth.com/skin-andbeauty-photos/common-skin-rashes.aspx, accessed on $11^{\text {th }}$ July, 2017). Based on the size, shape, pattern, distribution and consistency on the skin surfaces of the human beings, the skin rash can be differentiated and even named differently to indicate a particular syndrome. For example, the skin rash conditions may be termed as heat rash, acne, eczema, shingles, ringworm, psoriasis, hives, etc. Furthermore, the skin rash can conveniently be classified as primary lesions and secondary lesions (Figure 1). Primary lesions are those which occur due to the disease or trauma and secondary lesions are progressed form of primary lesions. These
Submission Date: 31-08-2017; Revision Date: 08-11-2017; Accepted Date: 06-12-2017

DOI: 10.5530/ijper.52.3.60 Correspondence: Dr. Tamilvanan Shunmugaperumal, Department of Pharmaceutics, Lovely School of Pharmaceutical Sciences, Lovely Professional University, Jalandhar-New Delhi G.T. Road, Phagwara-144411, Jalandhar, Punjab, INDIA Phone: +918699945904 E-mail: tamilvanan1@ yahoo.co.in

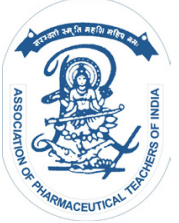

www.ijper.org 


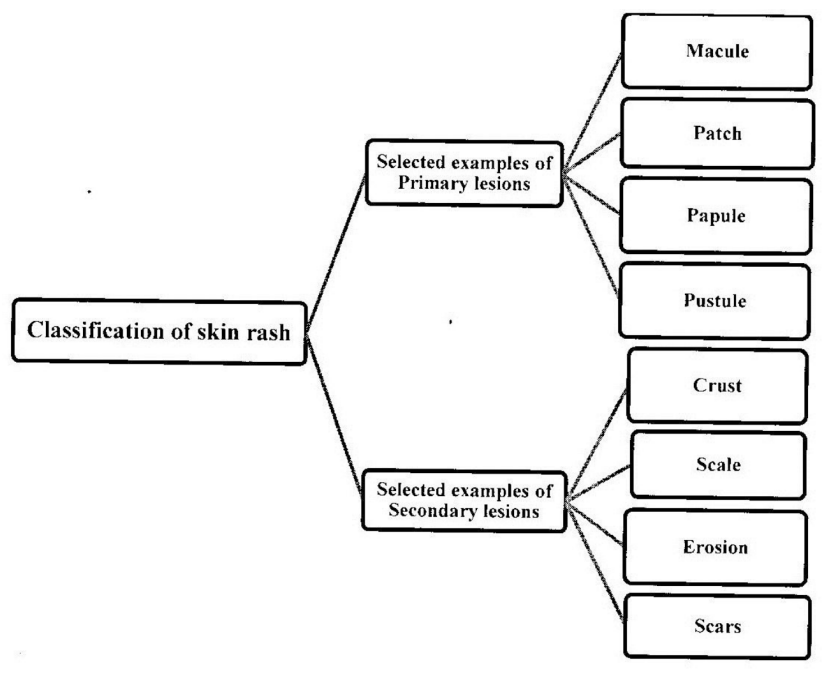

Figure 1: Selective classification of skin rash.

lesions get worse by infection, injury or by other external factor (extracted from http://howshealth.com/ types-of-skin-rashes-pictures-terms/, accessed on $20^{\text {th }}$ July, 2017).

In order to treat skin rash conditions, both allopathicand-ayurvedic-based topical formulations are available in the market as over-the-counter (OTC) products. It is in the hand of the consumer who is having the skin rash to select the particular type of formulations. Sometimes, the persons with skin rash may prefer to apply the topical formulations over the affected skin areas particularly at night time. Very few of them like to use the oral formulations such as tablets and capsules to manage the skin rash conditions although the selection of oral versus topical formulations purely depends on the prescriber's hand provided the skin rash affected person visit any dermatologist in a clinical set up.

A silent, comprehensive and semi-systematic questionnaire-based survey was conducted from August $16^{\text {th }}$ to September $10^{\text {th }}, 2016$ within a residential University, called as Lovely Professional University (LPU), situated at Phagwara, Jalandhar, Punjab, India. The LPU is one of the multi-cultured, very vigorous campus assembling with inter-and intra-state student communities from India as well as many countries of the world. This University admits students for number of under-graduate, post-graduate and $\mathrm{Ph} \mathrm{D}$ programs. About 3500 numbers of faculty and staff members are associated with the LPU to run all of these courses and they have engaged in transferring the knowledge to the young energetic student communities. Hence, the LPU is the vital place where the questionnaire-based survey study could be made to see the impact of allopathic-and-ayurvedicbased topical formulations used to manage the skin rash conditions by the under-and post-graduates as well as Ph D degree students.

The aims of the current questionnaire-based survey study are (1) to make an one-to-one interaction with the participants of the LPU student communities for knowing the range of topically applied allopathic and/ or ayurvedic formulations used for skin rash condition management, (2) to distribute the questionnaire containing the skin rash-related questions among the participants of LPU and (3) to analyse the responses provided by the LPU participants in terms of age, gender, education levels, awareness about topical formulations, contradictions, product safety, etc.

\section{METHODS}

A cross-sectional survey study was made inside the campus LPU campus by distributing the printed hard copies containing the skin rash related questions to the student communities. The student participants were selected randomly and the participant's education at LPU broadly comprised the disciplines of pharmacy, computer science, agriculture, civil engineering, architecture, etc. To further simplify the survey study analysis, the student participants were again segregated and provided the designation as pharmacy and non-pharmacy backgrounds. Although the printed hard copies containing the skin rash related questions were given to students of all disciplines of LPU, only 145 students had shown their interest (comprising 86 pharmacy students and 59 non-pharmacy students) and out of that 76 were female participant. The participant's age were ranging from 18 to 25 years.

A questionnaire was developed comprising of 14 questions under three sections including socio-demograpic and economic data (age, gender and education), frequency of topical OTC product usage and allopathic or ayurvedic product information (Table 1). Out of 14 questions, four questions were close-ended questions and remaining ten were open-ended questions. Close-ended questions are those which can be answered by a simple "yes" or "no," while open-ended questions are those which require more thought and more than a simple one-word answer(extracted from http://examples.yourdictionary. $\mathrm{com} /$ examples-of-open-ended-and-closed-ended-questions.html\#A7UMe2v6B0rT'Tpmt.99, accessed on 3-82016). In simpler words, Open-ended questions require a response with more depth and a lengthier response whereas close-ended questions can be answered in only one word or very short phrase.

In the current survey, the use of allopathic-and ayurvedic-based topical dosage forms by the participants 


\begin{tabular}{|c|c|c|c|c|}
\hline No. & \multicolumn{4}{|c|}{$\begin{array}{l}\text { Parameters and their choices } \\
\text { Name: }\end{array}$} \\
\hline 1. & \multicolumn{4}{|c|}{ Sex } \\
\hline & Male & \multicolumn{3}{|c|}{ Female } \\
\hline 2. & \multicolumn{4}{|c|}{ Age } \\
\hline \multirow[t]{3}{*}{3.} & \multicolumn{4}{|c|}{ Your highest level of education? } \\
\hline & Higher secondary & \multicolumn{2}{|c|}{ Senior secondary } & Graduate \\
\hline & Post graduate & \multicolumn{2}{|c|}{ M.phil } & Ph.D \\
\hline \multirow[t]{3}{*}{4.} & \multicolumn{4}{|c|}{ Are you suffering from any skin rash } \\
\hline & Less than once a month & \multicolumn{3}{|c|}{ several times a month } \\
\hline & Almost every day & \multicolumn{3}{|c|}{ Almost never } \\
\hline \multirow[t]{3}{*}{5.} & \multicolumn{4}{|c|}{ What type of skin care products have you used? } \\
\hline & Gels & \multicolumn{3}{|c|}{ Liquid } \\
\hline & Cream & \multicolumn{3}{|c|}{ Oinment } \\
\hline \multirow[t]{2}{*}{6.} & \multicolumn{4}{|c|}{ How frequently you use the skin care products. } \\
\hline & Everyday & \multicolumn{3}{|c|}{ Whenever necessary } \\
\hline \multirow[t]{2}{*}{7.} & \multicolumn{4}{|c|}{ Do you see any significant change after use of the skin care product? } \\
\hline & Yes & \multicolumn{3}{|c|}{ No } \\
\hline \multirow[t]{2}{*}{8.} & \multicolumn{4}{|c|}{ Are you using any Ayurvedic skin care product } \\
\hline & Yes & \multicolumn{3}{|c|}{ No } \\
\hline \multirow[t]{3}{*}{9.} & \multicolumn{4}{|c|}{ Do you feel Allopathic products are superior than Ayurvedic products? } \\
\hline & Yes & \multicolumn{3}{|c|}{ No } \\
\hline & \multicolumn{4}{|c|}{ Not known } \\
\hline \multirow[t]{2}{*}{10.} & \multicolumn{4}{|c|}{ Do you notice any side effects while using the skin care products } \\
\hline & Yes & & & \\
\hline 11. & How mar & kin care prod & ts do you use & \\
\hline & $2-3$ & & & \\
\hline & $3-5$ & & More & \\
\hline 12. & & w long have & ou been using & \\
\hline & Less than One month & One month & Six months & One year \\
\hline 13. & Why do you feel Allc & ic products & e superior than & products. \\
\hline 14. & Name som & kin care prod & ts that you use & \\
\hline
\end{tabular}

was assessed in the following manner. A one-to-one interaction was being made to know about the adverse effect, contraindications and awareness about the use of these topical dosage forms for skin rash management without any hesitations, meaning that even the participants were also allowed to choose multiple answers. It should be added that no question was framed to ask about the participants' residence.

\section{Data analysis}

Mean and standard deviation values for age of participants were calculated using a MS excel program. The education and knowledge which are included as one of the question of the questionnaire was identified using Kendall's regression for correlation. Irrespective of the participants' departments/disciplines, the results are presented in a combined manner in this report as there were no significant differences in the answers given for the questions asked to the participants.

\section{RESULTS}

The socio-demographic data of the students who have participated in the current questionnaire-based survey study is shown in Table 2. Irrespective of the gender differentiation, the average age of the male and female students was found to be 21.5 years. With the lone exception of a $\mathrm{Ph} \mathrm{D}$ degree student, the remaining all students participated in the survey study possess the educational level starting from higher secondary to post-graduate degree. 


\begin{tabular}{|c|c|c|c|c|c|c|c|}
\hline \multirow[t]{2}{*}{ Characteristics } & \multirow[t]{2}{*}{ Limits } & \multicolumn{2}{|c|}{ Total responds } & \multicolumn{2}{|c|}{ Pharmacy students } & \multicolumn{2}{|c|}{ Non-pharmacy students } \\
\hline & & $\begin{array}{c}\text { Number of } \\
\text { cases }\end{array}$ & percentage & $\begin{array}{c}\text { Number of } \\
\text { cases }\end{array}$ & percentage & $\begin{array}{c}\text { Number of } \\
\text { cases }\end{array}$ & percentage \\
\hline \multirow{3}{*}{$\begin{array}{c}\text { Age } \\
\text { (in years) }\end{array}$} & Below 18 & 20 & $13.8 \%$ & 13 & $8.9 \%$ & 07 & $4.8 \%$ \\
\hline & $19-21$ & 47 & $32.4 \%$ & 25 & $17.2 \%$ & 22 & $15.1 \%$ \\
\hline & $22-25$ & 78 & $53.8 \%$ & 29 & $20 \%$ & 49 & $33.7 \%$ \\
\hline \multirow[t]{2}{*}{ Gender } & Male & 69 & $47.5 \%$ & 38 & $26.2 \%$ & 31 & $21.3 \%$ \\
\hline & Female & 76 & $52.4 \%$ & 46 & $31.7 \%$ & 30 & $20.6 \%$ \\
\hline \multirow[t]{6}{*}{ Education } & Higher secondary & 12 & $8.2 \%$ & 09 & $6.2 \%$ & 03 & $2.0 \%$ \\
\hline & Senior secondary & 26 & $17.9 \%$ & 17 & $11.7 \%$ & 09 & $6.2 \%$ \\
\hline & Graduate & 89 & $61.3 \%$ & 49 & $33.7 \%$ & 40 & $27.5 \%$ \\
\hline & Post graduate & 17 & $11.7 \%$ & 09 & $6.2 \%$ & 08 & $5.5 \%$ \\
\hline & Ph.D & 01 & $0.6 \%$ & 01 & $0.6 \%$ & - & - \\
\hline & M.phil & - & - & - & - & - & - \\
\hline
\end{tabular}

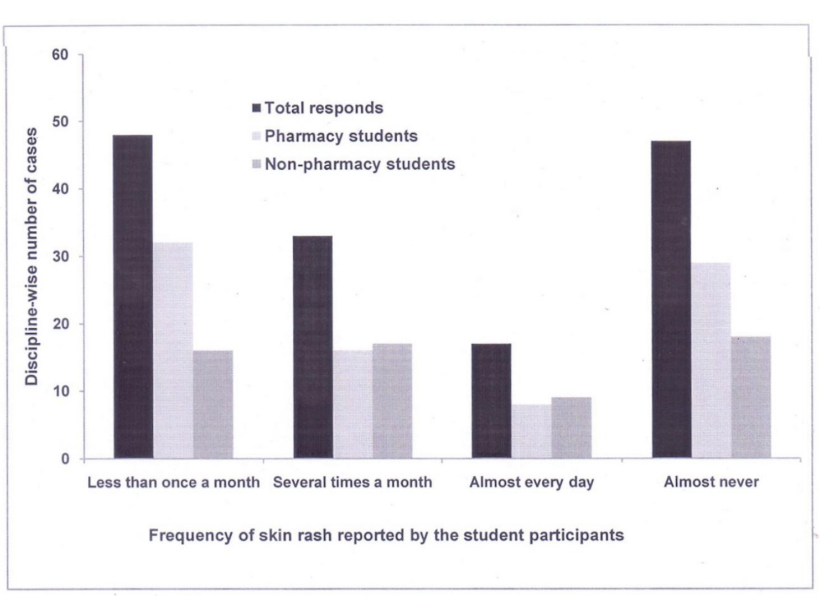

Figure 2: Skin rash conditions reported by the student participant.

The skin rash conditions observed on the skin surface of the student participants was segregated based on pharmacy and non-pharmacy disciplines as well as the time frequency of skin rash (Figure 2). Out of 17 students, 8 participants from pharmacy department and 9 participants from non-pharmacy departments stated that they suffered from skin rash conditions nearly every day. Similarly, out of 33 total respondents, 16 participants from pharmacy department and 17 from non-pharmacy department confessed that they suffer from skin rash conditions several times a month. Furthermore, 32 participants from pharmacy department and 16 participants from non-pharmacy department (out of 48 total respondents) felt skin rash conditions less than oncea-month. Interestingly, out of 47 total respondents, 29 participants from pharmacy department and 18 participants from non-pharmacy departments indicated that they almost never experienced any symptoms leading to the skin rash conditions.

\section{DISCUSSION}

For treating acute and chronic skin rash conditions occurring over the topical skin surfaces of human body, a non-pragmatic management system comprising the use of allopathic and ayurvedic topical formulations either alone or along with systemically administered drug products was followed depending on the intensity of skin rash of the individuals. The skin rash containing individuals usually think that the skin condition would be of manageable by the application of commercially available topical OTC products. Moreover, the topically applied allopathic and ayurvedic formulations is in general not being associated with any recognized adverse effects that are routinely being observed after the systemic formulations intake via oral-and otherroutes. In terms of safety profile, the ayurvedic topical formulations are most preferred medication for the management of skin rash conditions raised due to the intake and/or contact of toxic chemicals, sun rays, harmful microorganisms or the exposure to heavy metals, noxious gases and waste products from chemical and leather industries.

In this present survey study, a joint approach of nomothetic (group level) and idiographic (individual level) analysis was carried out by distributing questionnaire to pharmacy and non-pharmacy student participants living in an academic system. By means of promoting the thinking level of the student participants over the topical allopathic and ayurvedic skin rash products, this survey study tries to make an understanding of the topically applied medications used by the participants, 
their possible adverse effects on long term usage and their management in skin rash conditions. The individual level (idiographic) analysis uses a clear-cut interaction in terms of productive talking between the survey taker and the student participants through the already developed questionnaire. On the other hand, the group level (nomothetic) survey study gives a realistic analysis in terms of age, sex, education level and medication usage frequency. A similar type of using the nomothetic and idiographic approaches was successfully applied originally in Virtual Human ( $\mathrm{VH}$ ) technology study conducted by Wandner et al (2015) ${ }^{1}$ and followed by our research group (Tamilvanan and Puja, 2016). ${ }^{2}$ The present survey study also contains questions related to the participants own perception on skin rash conditions and their readiness to report topical skin rash formulations and these questions were asked to the pharmacy and nonpharmacy participants. The open-ended questions were also asked in the following specific categories in order to know the participants understanding to use the topical skin rash formulations.

1. Perception about skin rash conditions,

2. Familiar/non-familiar about the adverse effects of topical ayurvedic and allopathic skin rash managing products and

3. Using frequency of skin rash topical products.

In this way, the present survey study expounded the usage of the $\mathrm{VH}$ technology intervention to make an understanding of the topical OTC skin rash products used by the educated and young student participants of the LPU.

In India, topical formulations in the form of cream, gel and ointment containing either allopathic-or ayurvedicbased active pharmaceutical ingredients (API) are marketed as OTC products in most of the pharmacy stores across different states for the management of skin rash conditions. Table 3 shows the list of topical formulations used by the students who have participated in the survey study. Without knowing the root cause of skin rash symptom, the student participants were simply purchased the OTC topical formulation from the pharmacy stores and used the products just by applying it onto the affected skin area in two-three times a day until they felt that the skin rash conditions was managed. The management criteria set by the participants include the non- appearance of any greedy feeling over the skin rash affected area, change of coloration before and after applying the purchased OTC formulation over the affected skin area, complete disappearance of roughness over the affected skin area, stoppage of whale formulation around the affected skin rash area, etc. Sometimes,

\begin{tabular}{|c|c|}
\hline \multicolumn{2}{|c|}{ Table 3: Topical formulations used by participants. } \\
\hline Allopathic-based & Ayurvedic-based \\
\hline $\begin{array}{c}\text { Desonate (Desonide, Bayer } \\
\text { health care pharmaceutical } \\
\text { Inc., USA) }\end{array}$ & $\begin{array}{c}\text { Kailas (Ayurved } \\
\text { Sumshodhanalaya Pvt.Ltd, } \\
\text { India) }\end{array}$ \\
\hline $\begin{array}{c}\text { Vanos (Fluocinonide, Medicis } \\
\text { pharmaceutical corporation, } \\
\text { USA) }\end{array}$ & $\begin{array}{c}\text { Herbomineral (J and J } \\
\text { Dechane laboratories Pvt. Ltd, } \\
\text { India) }\end{array}$ \\
\hline $\begin{array}{c}\text { Elocon (Mometasome, Merck } \\
\text { and co., Inc., USA) }\end{array}$ & $\begin{array}{c}\text { Takzema (Dhanalakshmi and } \\
\text { corporation, India) }\end{array}$ \\
\hline $\begin{array}{c}\text { Anusol-HC (Hydrocorticone, } \\
\text { Johnson and Johnson, USA) }\end{array}$ & $\begin{array}{c}\text { Imupora (Charak Pharma Pvt. } \\
\text { Ltd, India) }\end{array}$ \\
\hline $\begin{array}{c}\text { Cutivate (Fluticasone, } \\
\text { PharmaDerm, USA) }\end{array}$ & $\begin{array}{c}\text { Nimrah (Kama and Ayurveda } \\
\text { corporation, India) }\end{array}$ \\
\hline
\end{tabular}

curing of wound or stoppage of itching sensation produced as skin rash conditions was considered by the student participants as the basis of their judgment to decide which topical OTC formulation was good and effective. It is very sad to note that all the young and educated student participants did not know about the adverse effects of the applied topical OTC formulation. Even some of the non-pharmacy participants believed the ayurvedic based topical OTC formulations were better in terms of fulfilling the management criteria set by the student participants themselves (Criteria as mentioned above). However, most of the pharmacy participants while interacting with them, they have indicated that no clear-cut difference was noticed between the therapeutic effects shown by the allopathicbased topical OTC products and the ayurvedic-based topical OTC products. Fittingly, the pharmacy participants did also not know much about the adverse effects of topically applied allopathic or ayurvedic-based formulations. But, in general, the pharmacy participants were also felt that the ayurvedic-based products are better than that of the effects produced by the allopathic-based topical products in treating skin rash conditions.

One of the most interesting points noted from this survey study was that there was an occurrence of the seasonal variation in the skin rash conditions. Irrespective of the pharmacy-and non-pharmacy-based student participants, it is the general belief that the skin rash condition was very commonly occurred during winter season (November-March) rather than summer season (AprilSeptember). In this context, the switching of one OTC products to another OTC product was also found to be very common among the student participants residing inside the LPU campus. That too, frequent changeover of the topical OTC formulations (from allopathic to ayurvedic and vice versa) was routinely a common 
practice done by the student participants. In spite of this kind of switch over process, the common criteria set by the student participants for the skin rash management remained the same. One more pitying observation noted from this present survey study was that most of the participants (about 88\%) did not consult the skin specialists before started using the topical OTC formulation. The remaining $22 \%$ of the student participants did consult the skin specialist for their skin rash conditions but the participants were not asked/ informed about the adverse effects of the prescribed topical formulations. On one side, the student participants were purchased topical OTC formulations by themselves and they were totally ignoring the leaflet information present inside the package of the topical OTC formulations. On the other side, the student participants were also not gained any information about the skin rash treating topical OTC formulations from the physician (skin care specialist) or from pharmacist who sold the products to the participants. . It can be concluded that although self-medication awareness to treat their skin rash conditions is fairly reached to the student communities, the consumers should read the drug safety profile through leaflet information present inside the package of the topical OTC formulations.

\section{Funding Sources}

None.

\section{Authors' Contributions}

Tamilvanan S. conceived the study design and wrote the manuscript. Malonje Daka performed the survey study by distributing the questionnaire to the students and Puja Chanda helped to draft the manuscript. All authors read and approved the final manuscript.

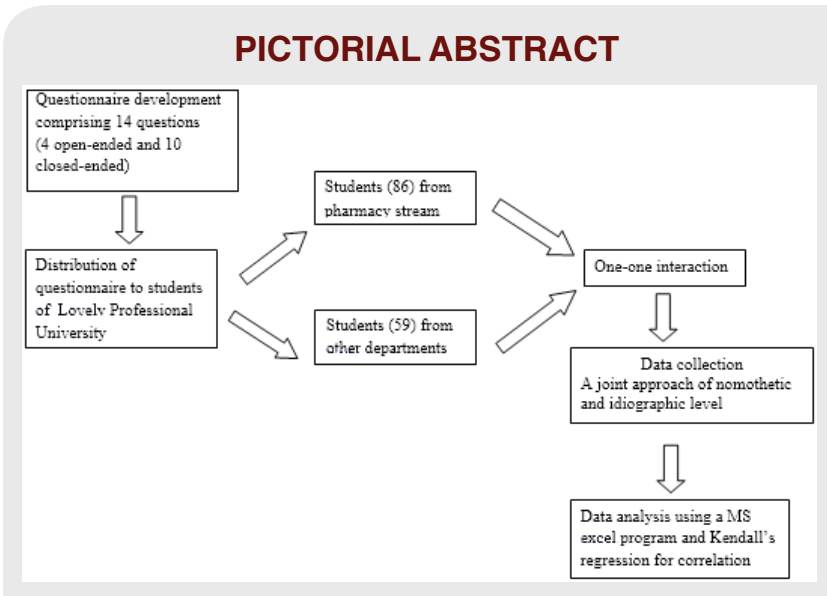

\section{CONCLUSION}

The vital informations such as self-medication awareness, product's side effects, visitation to skin specialists, etc., concerning the usage of topical OTC formulations by the student community of LPU to manage their skin rash conditions were analyzed through the questionnaire-based survey study. Providing a prolonged and sustainable awareness program might be of helpful to the students to understand the root cause of skin rash conditions and the way to prevent the syndrome progression further.

\section{ACKNOWLEDGEMENT}

The support given by the student community residing inside the LPU campus to conduct this questionnairebased survey study was acknowledged.

\section{CONFLICT OF INTEREST}

The authors report no conflicts of interest to disclose.

\section{ABBREVIATIONS}

API: Active pharmaceutical ingredients, LPU: Lovely Profession University, OTC: Over-the-counter, VH: Virtual Human.

\section{REFERENCES}

1. Wandner LD, Torres CA, Bartley EJ, George SZ, Robinson ME. Effect of a Perspective-Taking Intervention on the Consideration of Pain Assessment and Treatment Decisions. J Pain Res 2015; 8: 809-818.

2. Tamilvanan S, Puja C. Awareness and usage of over-the-counter pain-killer products by Indian University students: A questionnaire-based survey study. THE INDIAN PHARMACIST, Vol.XIII, No. 08, Page No. 45-51, February 2016.

\section{SUMMARY}

- Identification of lead molecules against therapeutic targets like PRR11 of cancer is an essential area of today's research.

- In this study, application of protein modelling tools for homology modelling and threading approaches determined the 3D structure of PRR11.

- Screening of small chemical molecule library (ZINC database) against ligand binding sites of PRR11 explored the five best lead molecules (28863059, 79642438, 27766155, 27855322 and 28365298).

- Computational prediction of ADME and adverse characters (MTIR) confirmed that all identified leads are safe for further in vitro and in vivo experimental evaluations. 


\section{About Authors}

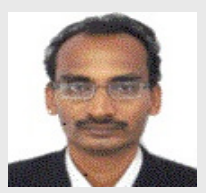

Tamilvanan Shunmugaperumal: Ph.D, works in the Department of Pharmaceutics at Lovely School of Pharmaceutical Sciences, Lovely Professional university, Jalandhar, Punjab, India. He possesses a vast experience in teaching and research activities which have generated so far more than 50 research papers, 06 single-authored international books, 06 single-and multi-authored book chapters in international books and few patents under filed states. He has supervised/supervising ph.D and master-degree students. He also travelled/worked in different countries like, Israel, France, Belgium, Ethiopia, USA and Malaysia.

Malonje Daka: Bachelor of Pharmacy, Lovely Professional University, Phagwara, Jalandhar, Punjab-144411.

Puja Chanda: Research Scholar in University Department of Pharmaceutical Sciences, Lovely Professional University, Phagwara, Jalandhar, Punjab-144411.

Cite this article: Shunmugaperumal T, Daka M, Chanda P. Self-Medication Awareness for Skin Rash Management by Indian University Students - A Questionnaire-Based Survey Study. Indian J of Pharmaceutical Education and Research. 2018;52(3):525-31. 